\title{
Risk factors and visual outcome in presenile cataract
}

\author{
Sonam Verma ${ }^{1}$, Nitin Nema ${ }^{2, *}$, Abha Verma ${ }^{3}$, Shachi Dwivedi ${ }^{4}$, Mayank Gupta $^{5}$ \\ ${ }^{1}$ Senior Resident, ${ }^{2}$ Professor, ${ }^{3}$ Associate Professor, ${ }^{4,5}$ Junior Resident, Dept. of Ophthalmology, Sri Aurobindo Medical College \\ \& PG Institute, Indore, Madhya Pradesh, India
}

*Corresponding Author: Nitin Nema

Email: nemanitin@yahoo.com

\begin{abstract}
Objective: To study the risk factors and visual outcome in patients of presenile cataract.

Materials and Methods: A cross sectional observational study was conducted between January 2016 and January 2017 at a tertiary health care centre. Patients with cataract between age 35 and 55 years were selected. Risk factors like diabetes mellitus, high myopia, dermatological diseases and tobacco consumption were noted. Visual acuity was recorded and a detailed examination of anterior and posterior segments was done. Patients underwent cataract surgery with intraocular lens implantation. Postoperative best-corrected visual acuity was noted.

Result: Out of 120 patients there were 47 males (mean age $45.43 \pm 6.79$ years) and 73 females (mean age $47.33 \pm 6.08$ years), mostly with bilateral eye involvement $(n=103)$. Most of the cases were idiopathic $(65.9 \%)$ whereas association of other risk factors in order of frequency was: tobacco consumption (10.8\%), high myopia and diabetes mellitus (7.5\% each), prolonged period of outdoor work and long-term steroid use (3.3\% each), and dermatological diseases (1.7\%). Using Annova test, a significant difference preoperative and postoperative vision was found amongst all age groups $(\mathrm{p}=0.032)$.

Conclusion: Tobacco consumption is a strong risk factor for cataractogenesis above diabetes mellitus and high myopia in presenile age group. A significant visual improvement results after cataract surgery and lens implantation.
\end{abstract}

Keywords: Presenile cataract, Tobacco consumption, Diabetes mellitus, High myopia.

\section{Introduction}

Cataract is a major cause of blindness worldwide with a greater prevalence in developing countries like India. ${ }^{1}$ Presenile cataract refers to an onset of this disease anytime from 35 years to 55 years of age. ${ }^{2}$

There are various risk factors for presenile cataract including family history, refractive error, metabolic diseases and atopy. Other risk factors include long-term use of corticosteroids. ${ }^{3}$ The development of cataract also depends upon the dose and the mode of administration of corticosteroid.

In India, almost $62.6 \%$ of blindness is attributed to cataract. ${ }^{4,5}$ It shows an earlier age of onset in India as compared to that in industrialized countries. Data from a study carried out in Punjab showed that the agespecific prevalence of cataract in India was three to six times higher than that in the Framingham Eye study in the United States. ${ }^{6}$ It suggests that the Indian population is either widely exposed to environmental risk factors or there is a genetic predisposition to cataract. The search for modifiable risk factors that affect the occurrence of cataract has led to the search of associations between cataract and diabetes, hypertension, body mass index, drug usage, severe dehydration crisis, gender, smoking, use of alcohol, exposure to UV light, childbearing and socioeconomic status.

Substance abuse like active smoking and alcohol use, and exposure to ultra violet $\beta$ (UV B) radiation also enhance the process of cataractogenesis. Exposure to Xrays and ionizing radiations can lead to rapid development of cataract. ${ }^{7}$ Presenile cataract is a serious and stressful morbidity as it affects the working and bread earning population of the society.

This study was conducted in order to analyze the various preventable risk factors that are associated with presenile cataract. Identifying and addressing to them may decrease the incidence of presenile cataract.

\section{Materials and Methods}

We conducted this cross-sectional observational study in a tertiary care hospital which included patients of either gender aged between 35 and 55 years who reported to the eye department from January 2016 to January 2017 with cataract. Those with a history of ocular trauma, congenital cataract, developmental cataract, intraocular inflammation or previous intraocular surgery were excluded from the study. The study was approved by the institutional ethical committee and followed the tenets of the declaration of Helsinki.

After procuring the informed and written consent, each patient was evaluated. A thorough history was taken regarding the risk factors such as diabetes mellitus, high myopia, occupation, dermatological disease (atopic dermatitis) and smoking. Patients were also inquired about the history of chemotherapy, radiotherapy, chronic intake of corticosteroids, substance abuse and history of early onset of cataract in the family.

The visual acuity was tested using Snellen's visual acuity chart and the best-corrected visual acuity (BCVA) were assessed preoperatively. The anterior segment of the patients was examined using a slit-lamp 
biomicroscope and the intraocular pressure was measured using an applanation tonometer.

The pupils were dilated using a combination of topical phenylephrine-tropicamide eye drop. On acquiring complete pupillary dilation examination on slit-lamp was repeated to assess the type of cataract. Moreover the posterior segment was examined using an indirect ophthalmoscope and slit-lamp and $90 \mathrm{D}$ lens.

Biometry of all the patients was done using a handheld automated keratometer and an A-scan. The patients with an axial length more than $26 \mathrm{~mm}$ were regarded as high myopes. Routine preoperative investigations included complete blood counts, blood sugar level and blood pressure recording. Patients with a known history of diabetes mellitus or having a fasting blood sugar $\geq 126 \mathrm{mg} / \mathrm{dL}$ or glycosylated haemoglobin $>6.5 \%$ were labelled as diabetics.

The patients were counselled for the surgery and briefed about phacoemulsification and manual small incision cataract surgery (SICS) with intraocular lens implantation. Depending upon the patient's choice, the preferred procedure was performed. The best-corrected visual acuity was noted on the first postoperative day and finally on four weeks postoperatively.

In order to calculate the mean age of both the sexes and compare them with the frequency of risk factors, descriptive analysis was done. Frequency of different types of cataracts was compared with genders using Chi square test. In order to compare the preoperative and postoperative visual acuity Annova test was done.

\section{Observations}

Out of a total of 120 patients there were 47 males (39.2\%) and 73 females $(60.8 \%)$. The mean age of males and females were $45.43 \pm 6.79$ and $47.33 \pm 6.08$ years, respectively. Of these, 32 patients $(26.7 \%)$ were in the age group of 35 to 40 years and 22 patients $(18.3 \%)$ in the age group of 41 to 45 years of age. However, the maximum number of patients $(35,29.2 \%)$ belonged to 46 to 50 years age group (Table 1).

Table 1: Age-wise distribution of patients

\begin{tabular}{|c|c|}
\hline Age group (in years) & No. of patients (\%) \\
\hline $35-40$ & $32(26.7)$ \\
\hline $41-45$ & $22(18.3)$ \\
\hline $46-50$ & $35(29.2)$ \\
\hline $51-55$ & $31(25.8)$ \\
\hline Total & $120(100)$ \\
\hline
\end{tabular}

Seventy nine $(65.9 \%)$ patients were not associated with any risk factor and designated as idiopathic (Table 2). A total of $13(10.8 \%)$ cases were tobacco abusers. There were $9(7.5 \%)$ patients each in high myopia and diabetes mellitus group. Four (3.3\%) patients were found to be field workers (who worked for six or more hours in field at least five days a week) and an equal number of them gave history of long-term corticosteroid use (who were on steroids for six or more months).

Table 2: Distribution of risk factors

\begin{tabular}{|l|c|}
\hline \multicolumn{1}{|c|}{ Risk factors } & No. of patients (\%) \\
\hline Idiopathic & $79(65.9)$ \\
\hline Tobacco consumption & $13(10.8)$ \\
\hline High myopia & $9(7.5)$ \\
\hline Diabetes mellitus & $9(7.5)$ \\
\hline Field worker & $4(3.3)$ \\
\hline Long-term steroid intake & $4(3.3)$ \\
\hline Dermatological diseases & $2(1.7)$ \\
\hline Total & $120(100)$ \\
\hline
\end{tabular}

Out of a total of 120 cases, 103 (85.8\%) patients presented with bilateral cataract. The Pearson $\mathrm{R}$ value was -0.036 with asymptotic error of 0.092 when laterality was compared with sex of the patients. It was observed that $77(64.2 \%)$ cases had nuclear sclerosis whereas $26(21.7 \%)$ patients had cortical cataract (Table 3). Seventy one patients $(59.2 \%)$ underwent phacoemulsification and 49 patients (40.8\%) were operated by manual SICS technique.

Table 3: Gender-wise distribution of type of cataract

\begin{tabular}{|l|c|c|c|}
\hline \multicolumn{1}{|c|}{ Type of cataract } & Male & Female & Total (\%) \\
\hline Posterior subcapsular & 5 & 4 & $9(7.5)$ \\
\hline Nuclear sclerosis & 28 & 49 & $77(64.2)$ \\
\hline Cortical cataract & 11 & 15 & $26(21.7)$ \\
\hline Hypermature cataract & 1 & 5 & $6(5)$ \\
\hline $\begin{array}{l}\text { Posterior polar } \\
\text { cataract }\end{array}$ & 2 & 0 & $2(1.6)$ \\
\hline
\end{tabular}

Pearson Chi square $=6.539, \mathrm{df}=5$, Asymp sig $=0.257$

The preoperative and postoperative BCVA between the various age groups was compared by applying Annova test. It was found not to be significant. However, the visual improvement in the four age groups was found to be significant by comparing the preoperative and postoperative visual acuity $(\mathrm{p}=0.032)$.

The final visual acuity ranged from $6 / 6$ to $6 / 12$ in 119 out of 120 patient $(99.2 \%)$, except for 1 case with primary posterior capsular opacification. In this patient the BCVA was $6 / 18$ the cause of which was explained to the patient.

\section{Discussion}

Cataract accounts for 17.6 million cases worldwide of which 9-12 million bilaterally blind persons are present in India. ${ }^{8}$ It is estimated that 2 million new cases of cataract are being added to this burden in India every year, ${ }^{9}$ meanwhile 4 million people turn blind due to cataract every year. ${ }^{10}$ According to World Health Organization the blind population will double by 2020 because of the rise in population and longevity. 
The greater exposure to risk factors such as ultraviolet light, poor diet, frequent episodes of dehydration, and more frequent childbearing explain why cataract is more common in developing countries than in industrialised nations and why cataract develops at a younger age. ${ }^{7}$ Onset of cataract causes progressive loss of vision which with progression makes daily work increasingly difficult especially in the young population earning livelihood for their families. If left untreated, it ultimately may even endanger their jobs, deteriorating the quality of life of the patients and their families. It not only causes fall in the per capita income but also brings down the national economy at a larger level by increasing the percentage of dependent population. Therefore, visual restoration surgery is performed without any delay in patients of presenile cataracts.

The estimates indicated that delaying the onset of cataract by ten years could reduce the need for surgery by $45 \%$. Therefore, primary prevention of cataract is an optimal approach and could be more cost-effective than cataract surgery in blindness prevention. ${ }^{11}$ These are the reasons for which we need to explore and find the modifiable risk factors in order to prevent this morbidity.

In our study we observed a female preponderance for reasons unknown. A study from South India also found a female predisposition for presenile cataract. ${ }^{3}$ Tsai et al reported the average age of $45.5 \pm 7.6$ years for presenile group, ${ }^{12}$ which is almost the same as in our patients. However, there was an earlier age of onset of cataract in male patients as compared to females as reported by Kalzuny et al. ${ }^{13}$

Surprisingly, we found a strong association of tobacco consumption (13 out of $120,10.8 \%$ ) as a risk factor for presenile cataract superseding diabetes (9 out of $120,7.5 \%)$ as reported in other studies. ${ }^{3,6,7,14}$ The human cataractous lens shows almost $50 \%$ deterioration in calcium-ATPase activity resulting in intralenticular calcium deficiency as compared to normal lens. It may be correlated to a study on animal model which demonstrated cataractogenesis as a result of disrupted ocular calcium homeostasis due to cyanide exposure from tobacco. ${ }^{15}$ Amongst the modifiable environmental factors tobacco consumption has been proved to be responsible for cataract. ${ }^{16}$ Accumulation of sorbitol within the lens changes its hydration and alters its metabolism in diabetic cataract. In our study we also noted an equal percentage of high myopes (9 out of $120,7.5 \%$ ) as diabetics with presenile cataract. Praveen et al reported myopia to be a risk factor for presenile cataract. ${ }^{7}$ Endoplasmic reticulum stress and unfolded protein response on the lens epithelium results in an early onset of cataract in high myopia. ${ }^{17}$ However, in our study in majority of cases (79 out of $120,65.9 \%$ ) no definite cause for presenile cataract formation could be found. A similar observation is reported in other previous studies. ${ }^{5-7,14,18,19}$ Further research is needed to search for other risk factors for formation of presenile cataract so that the percentage of idiopathic cases of cataractogenesis decreases in future.

Many studies have been done to explore the genetic risk factors for development of presenile cataract and they have reported varied results in terms of regions and races., ${ }^{20-22}$ Galactosaemia, similar to diabetes mellitus, is a metabolic disorder that causes improper galactose metabolism and a predisposition to cataract formation..$^{20,21}$ The most common and severe form is classical galactosaemia due to mutation in the GALT gene that leads to no GALT activity proving to be lethal. The other less common types are galactosaemia type II due to mutation in the GALK1 (galactokinase) gene and galactosaemia type III due to mutation in the GALE (galactose epimerase) gene. In galactosaemia, early and presenile cataract formation occurs due to deficient GALT enzyme. In our recently published study we found no statistically significant difference in the occurrence of GALT gene mutation between patients with idiopathic presenile cataract and controls. ${ }^{23}$ However, large population based studies are needed to find other genes and environmental factors associated with presenile cataract.

\section{Conclusion}

In a large number of cases of presenile cataract the etiology remains idiopathic. Addiction to tobacco has an association with causation of early onset cataract. Excellent visual restoration is achieved by cataract surgery with lens implantation.

\section{References}

1. Foster A, Gilbert C, Johnson G. Changing patterns in global blindness: 1988-2008. Community Eye Health. 2008;21(67):37-39.

2. Stevens RE, Datiles MB, Srivastava SK, Ansari NH, Maumenee AE, Stark WJ. Idiopathic presenile cataract formation and galactosaemia. Br J Ophthalmol. 1989;73:48-51.

3. Manoj Vasudevan, (Maj) G. Premnath. A Prospective Observational Study to Analyze the Causes and Types of Pre Senile Cataract in South Indian Patients. Journal of Evolution of Medical and Dental Sciences. 2014;3(53):12308-12315. DOI: 10.14260/jemds/2014/3626

4. Verma R, Khanna P, Prinja S, Rajput M, Arora V. The National Programme for Control of BlindneAss in India. The Australasian Medical Journal. 2011;4(1):1-3. doi:10.4066/AMJ.2011.505.

5. Thompson JR. The demand incidence of cataract in Asian immigrants to Britain and their descendants. $\mathrm{Br} \mathrm{J}$ Ophthalmol. 1989;73:950-4.

6. Chatterjee A, Milton RC, Thyle S. Prevalence and aetiology of cataract in Punjab. Br J Ophthalmol. 1982;66:35-42.

7. Praveen MR, Shah GD, Vasavada AR, Mehta PG, Gilbert C, Bhagat G (2010) A study to explore the risk factors for the early onset of cataract in India. Eye (Lond) 2010;24:686-694. 
8. Taleb A, Ávila M, Almeida R, Bicas H (2007) As Condições da Saúde Ocular no Brasil International Standard Book (Publicação oficiDl do Conselho Brasileiro de 2iDlmologiD).

9. Salomao SR, Cinoto RW, Berezovsky A, Araujo-Filho A, Mitsuhiro MR, et al. (2008) Prevalence and causes of vision impairment and blindness in older adults in Brazil: He Sao Paulo Eye Study. Ophthalmic Epidemiol. 2008; 15:167-175.

10. Minassian DC and Mehra V. 3.8 Million blinded by cataract each year. Projections from the first epidemiological study of incidence of cataract blindess in India. $\mathrm{Br}$ J Ophthalmol. 1990;74:341-343.

11. Cataract Panel. 1983. Report. Vision research: a national dan 1983-87. Part 3. NJHpubl. 83-2473. Washington, DC: US DHHS.

12. Tsai CK, Teng MC, Wu PC, Kuo HK. Clinical features of patients featuring cataracts in a myopia-endemic area of Taiwan. Chang Gung Med J. 2006;29:406-411.

13. Kalzuny JJ. Mean age of patients with senile and pre senile cataract in clinical material from 1987-1992. Klin Oczna. 1993;95:277-280.

14. Rahman A, Yahya K, Shaikh A, Fasih U, Zuberi BF. Risk factors associated with Pre-senile Cataract. Pak J Med Sci. 2011;27(1):145-148.

15. Okoliea NP, Audua K. Correlation between cyanideinduced decreases in ocular Ca2+-ATPase and lenticular opacification. JMBR. 2004;3(1):37-41.

16. Wu R, Wang JJ, Mitchell P, Lamoureux EL, Zheng Y, Rochtchina E, et al. Smoking, socioeconomic factors, and agerelated cataract: The Singapore Malay Eye study. Arch Ophthalmol. 2010;128:1029-1035.

17. Yang J, Zhou S, Gu J, Guo M, Xia H, Liu Y. UPR Activation and the Down-Regulation of $\alpha$-Crystallin in Human High Myopia-Related Cataract Lens Epithelium.
Nagaraj R, ed. PLoS ONE. 2015;10(9): e0137582. doi:10.1371/journal.pone.0137582.

18. Younan C, Mitchell P, Cumming RG, Rochtchina E, Wang JJ. Myopia and incident cataract and cataract surgery: The blue mountains eye study. Invest Ophthalmol Vis Sci. 2002;43:3625-3632.

19. Kanthan GL, Mitchell P, Burlutsky G, Wang JJ. Alcohol consumption and the long-term incidence of cataract and cataract surgery: the Blue Mountains Eye Study. Am J Ophthalmol. 2010;150:434-440.

20. Karas N, Gobec L, Pfeifer V, Mlinar B, Battelino T, Lukac-Bajalo J. Mutations in galactose-1-phosphate uridyl transferase gene in patients with idiopathic presenile cataract. J Inherit Metab Dis. 2003;26:699-704.

21. Lukac Bajalo J. Idiopathic presenile cataracts and galactosemia. Adv Clin Pathol. 1997;1(Suppl 1):L5.

22. López Valverde G, Garcia Martin E, Larrosa Povés JM, Polo Llorens V, Fernández Mateos J, Pablo Júlvez LE, et al. Correction: Study of Association between Pre-Senile Cataracts and the Polymorphisms rs2228000 in XPC and rs 1042522 in 553 in Spanish Population. PLoS ONE. 2017;12(1): e0171395. https://doi.org/10.1371/journal.pone.0171395

23. Nema N, Kumar R, Verma A, Verma S, Chaturvedi K. Association of presenile cataract with galactose-1phosphate uridyl transferase gene mutations. The National Medical Journal of India. 2017;30:73-5.

How to cite this article: Verma S, Nema N, Verma A, Dwivedi S, Gupta M. Risk factors and visual outcome in presenile cataract. Indian $\mathbf{J}$ Clin Exp Ophthalmol. 2018;4(4):450-453. 